\title{
Ambiguity Aversion and Cash Holdings
}

\section{$10 / 30 / 2013$}

\author{
Wolfgang Breuer $^{1}$, M. Oliver Rieger ${ }^{2}$, K. Can Soypak ${ }^{1}$ \\ ${ }^{1}$ RWTH Aachen University, Aachen, Germany; ${ }^{2}$ University of Trier, Trier, Germany
}

\begin{abstract}
Previous literature on cash management has revealed that cash holdings are treated like an insurance policy against liquidity shocks that limit future profitable investments. In a theoretical model based on this finding, we analyze how investors' attitude towards uncertain investment returns affects the valuation of cash and the amount of cash holdings. Consequently, we show empirically in a panel analysis that cash holdings indeed become less valuable with increasing ambiguity aversion. In line with the other studies from the catering literature, we also demonstrate that managers react accordingly and lower cash holdings if their investors are ambiguity averse. With several robustness tests we also address potential doubts concerning the quality of our data and analyze further implications of our theory.
\end{abstract}

JEL Classification: A12, D03, G35, Z10

Keywords: Ambiguity aversion, behavioral decision theory, cash policy, corporate finance. 


\title{
Ambiguity Aversion and Cash Holdings
}

\author{
05/08/2013
}

\begin{abstract}
Previous literature on cash management has revealed that cash holdings are treated like an insurance policy against liquidity shocks that limit future profitable investments. In a theoretical model based on this finding, we analyze how investors' attitude towards uncertain investment returns affects the valuation of cash and the amount of cash holdings. Consequently, we show empirically in a panel analysis that cash holdings indeed become less valuable with increasing ambiguity aversion. In line with the other studies from the catering literature, we also demonstrate that managers react accordingly and lower cash holdings if their investors are ambiguity averse. With several robustness tests we also address potential doubts concerning the quality of our data and analyze further implications of our theory.
\end{abstract}

JEL Classification: A12, D03, G35, Z10

Keywords: Ambiguity aversion, behavioral decision theory, cash policy, corporate finance. 


\section{Introduction}

The traditional corporate finance literature neglected to analyze determinants of cash policies for a long time. Mostly, cash is regarded as negative debt and therefore, it is considered to be a tool to reach the optimal leverage target (Opler et al., 1999; Acharya et al., 2007). Of course, under this assumption, debt redemption and cash holdings are substitutes and only net leverage should matter for the market value of a company.

However, the markets are far from being perfect and financially constrained firms do not always have access to external financing channels in times of need or they have to sell new securities for unreasonable prices to finance new investments or they have to terminate profitable investments too early due to liquidity constraints. Preserving liquidity serves in this sense as an insurance policy, which safeguards a firm against possibly terminating good projects early or issuing new equity or debt under unfavorable conditions (Holmstrom and Tirole, 1998). In these scenarios, companies may prefer to cut down dividends or share repurchases today in order to hoard cash for future investments.

Different papers have found empirical support for this story which we refer to as the precautionary motive of cash holdings (Keynes, 1936). For instance, Opler et al. (1999) demonstrated that growth firms with volatile cash flows are more likely to retain their earnings as cash instead of distributing them to shareholders. More recently, Bates et al. (2009) showed that firms started to hoard more cash in the last decade and this rise is related to increased opaqueness (high R\&D spending) and cash flow volatility. Due to augmented underinvestment (Myers, 1977) and asset substitution problems (Jensen and Meckling, 1976), these firms face larger agency costs of debt and they should respond to increased costs of external financing by building up cash reserves in order to avoid agency costs of debt. Furthermore, this relationship should disappear for unconstrained firms, as they already have enough funds in place or unutilized credit lines to implement value-increasing projects. Indeed, Almeida et 
al. (2004) advocates that the cash holding policy is sensitive to cash flow only for constrained firms, i.e. firms facing difficulties raising external funds (Han and Qiu, 2007).

Following these results, another branch of research has focused on the relation between cash holdings and the market value of a company. Although the literature in this field is relatively scarce, the empirical evidence suggests that investors of constrained firms benefit from cash holdings to a larger extent compared to the investors of non-constrained firms (Faulkender and Wang, 2006; Pinkowitz and Williamson, 2007; Denis and Sibikov, 2010). This result is consistent with earlier work analyzing the amount of cash holdings and it explains why constrained firms prefer to retain a larger portion of their earnings as cash.

Thus, until now, the literature on cash holdings has tried to justify large cash reserves with the precautionary motive story. Yet, these papers have not considered another important financial imperfection that might affect the valuation of cash and firms' cash policy as well. In imperfect markets with financial constraints, investors' bounded rationality would also play a role for the valuation of cash holdings and managers should try to satisfy investors' needs and secure their jobs. Thus, investors' preferences may have an impact on cash policies.

Interestingly, the cash holding decisions have not been dissected from this perspective, although there is extensive evidence that companies adjust other financial decisions such as dividend payouts (Baker and Wurgler, 2004) or mergers and acquisitions (Baker et al., 2009) according to investor preferences. Similarly, there is enough evidence showing that investors' reaction to corporate financial policies and the returns after the announcement of specific corporate events are correlated with their sentiment (see e.g., Becker et al., 2011, Bouwman et al., 2004).

In this paper, we want to close this research gap extending this so-called "catering" literature by investigating the connection between investor preferences and cash management. 
For this purpose, we analyze how the valuation of cash depends on investor preferences and how managers choose cash holding policies as a tool to satisfy investors.

Furthermore, the previous catering literature has neglected to discuss which aspects of investors' preferences are responsible for the investors' demand for certain financial policy decisions. Instead, they either focused on geographical or demographical aspects to identify certain clienteles with similar preferences which companies need to cater to in order to have higher returns (Graham and Kumar, 2006) or discussed how changes in market sentiment force managers to adjust their decisions (Baker and Wurgler, 2004). To our knowledge, Breuer et al. (2013) is the only paper to discuss the relevance of investors' risk and time preferences for investors' reaction to financial decisions (for the example of dividend policy) in a straightforward way. Breuer et al. (2013) utilize a unique dataset on actual (country-specific) preference parameters according to prospect theory (Kahmenann and Tversky, 1979). Similarly, this paper also elaborates on a specific aspect of investors' preference patterns (ambiguity aversion) that might affect the valuation of cash holdings. In a related manner, this paper also allows us to discuss whether management pays attention to investors' ambiguity preferences in the process of deciding cash holdings.

Last but not least, we can also contribute to the literature focusing on cross-country differences in corporate cash holdings examining whether investor preferences can explain cross-country differences in the valuation of cash holdings and in cash policies besides investor protection (Dittmar and Marth-Smith, 2007), the development of credit markets (see, e.g., Lins et al., 2010) or cultural aspects (see, e.g., Chen et al., 2013).

To recap, the contribution of our paper is threefold. First of all, our paper is the first one studying cash holdings as a vehicle to cater for investors' needs, as we analyze how investors value cash and whether managers correctly adapt cash holding policies to satisfy their investors. Secondly, emanating from the precautionary motive story for cash holdings, we 
connect investor preferences directly to cash management decisions both theoretically and empirically for the first time in the literature. This way, thirdly, we also offer an alternative explanation for cross-country differences in the valuation of cash and in cash holdings based on investor preferences and biases.

Our paper is organized as follows. In the next section, we present a theoretical model linking investors' ambiguity aversion to the valuation of cash. Section 3 describes the obtained data, our regression model and the initial results for our empirical analysis. Consequently, in Section 4, we discuss further implications of our theory and the robustness of our results. Section 5 concludes.

\section{The Behavioral Explanation for Cash Holdings: A Simple Model}

As we have mentioned above, some papers have demonstrated that the reaction to certain corporate events is not consistent over time and depends on the respective temporary investor sentiment. At the same time, certain demographic characteristics of investors such as age or income level are also instrumental again in understanding stock price movements after corporate events. Yet, other than Breuer et al. (2013), we are not aware of any attempt of investigating the relation between the actual investor preference parameters and different corporate financial decisions in a straightforward way. More astonishingly, the question of whether cash holding policies serve to catering purposes has not been discussed before us at all.

To fill these gaps, we want to analyze in this paper the impact of investors' ambiguity aversion on their attitude towards cash policies. As we discussed above, cash holdings are treated as an insurance tool against the illiquidity risks in imperfect markets according to the precautionary motive story. We argue that if an investor exhibits high ambiguity aversion, she prefers to limit investments with uncertain outcomes and to receive dividends instead (see also Breuer et al., 2013), since investment opportunities are afflicted with uncertainty. As a 
result, this would render cash holdings rather unnecessary, as future investments are not very valuable for ambiguity averse investors. In other words, if cash holdings serve as an important insurance tool against the risks of illiquidity in imperfect markets, their value should depend on investors' preferences towards ambiguity.

Now, we want to discuss this relation in detail in a theoretical setting. Our model is based on the same principles as the models of Almeida et al. (2004) or Han and Qiu (2007), but it additionally integrates investors' ambiguity preferences into the problem setting. Like these models, we also abstract from the managerial entrenchment problem and assume that managers choose the investment, cash and dividend policy in order to maximize the market value of the company and there are no conflicts of interest between managers and investors. Hence, we ignore agency problems between managers and investors, although empirical evidence suggests that cash holdings might amplify agency problems (Pinkowitz, 2002; Dittmar et al., 2003). We discuss this issue further in our empirical analysis.

Our model has a finite planning horizon. In the first period (period 1), the manager determines the amount of cash that she wants to retain in the company. At the beginning of the second period (period 2), she decides simultaneously how much the company should borrow and invest. In the following and last period (period 3), all uncertainty is resolved, investment projects are terminated and debt is going to be repaid (see also Figure 1).

\section{$>>$ Insert Figure 1}

In period 1 , the firm starts with an initial distributable free cash flow, $X \geq 0$. After holding some portion of $X$ as cash $(C)$, the rest is distributed as dividends. In period 2, $C$ is paid out to investors as dividends or deployed to finance new investments $(I)$ with uncertain earnings $g(I, \tilde{\varepsilon})$ where $\tilde{\varepsilon}$ describes the uncertainty of investment payoffs. The cash reserves $C$ are dissolved completely, because the company is terminated after the period 3. Furthermore, 
the company has current operations that can generate non-negative cash flow $(\tilde{c})$ during the first period as well and it can issue new debt $(B)$. With respect to cash flow $c$ in period 2, we assume this to be risky, but - in contrast to $g(I, \tilde{\varepsilon})$ - not to be uncertain. This means only $g(I, \tilde{\varepsilon})$ is afflicted with uncertainty. This assumption is easily justifiable, as a company can assess the return distributions of the cash flows from assets in place much easier after gaining experience based on the performance in the past and observed some error terms already, while new investments might have unforeseeable results for the company. Moreover, without loss of generality we assume - for ease of exposition $-\tilde{\varepsilon}$ and $\tilde{c}$ to be independent.

The interest rate for debt is equal to the riskless rate $R_{0}$, since we assume that creditors do not grant credits that cannot be repaid with certainty after period 3 . Hence:

$$
B \cdot\left(1+R_{0}\right) \leq I \cdot\left(1+R_{\text {liq }}\right)
$$

$R_{l i q}$ stands for the (riskless) return from investments, if the company is forced by debt holders to liquidate its investments. This occurs if investment returns $g(I, \varepsilon)$ in the third period are not high enough to repay outstanding loans including interest expenses, hence if $g(I, \varepsilon)<$ $B \cdot\left(1+R_{0}\right)$. We assume $R_{l i q}$ to be smaller than $R_{0}$, because otherwise there would be no risk for the company to lose money and it can borrow unlimited amount of credit as a result. Hence, no firm would be financially constrained in this case.

Since we have a three-period-model, we also assume that company operations are terminated at the end of period 3 after receiving returns from investments and after repaying outstanding debt. Taken together, a manager, whose task it is to maximize a representative investor's utility, faces the following optimization problem in period 1:

$$
\begin{aligned}
& Z(C, B(\tilde{c}, C), I(\tilde{c}, C))=X-C+\frac{1}{1+R_{0}} \cdot(C+E(B(\tilde{c}, C))-E(I(\tilde{c}, C, B))+E(\tilde{c}))+ \\
& \frac{f(\delta) \cdot E(g(I(\tilde{c}, C), \tilde{\varepsilon}))}{\left(1+R_{0}\right)^{2}}-\frac{E(B(\tilde{c}, C)) \cdot\left(1+R_{0}\right)}{\left(1+R_{0}\right)^{2}} \quad \text { s.t }
\end{aligned}
$$




$$
\begin{gathered}
I(\tilde{c}, C) \leq \tilde{c}+B(\tilde{c}, C)+C \\
B(\tilde{c}, C) \cdot\left(1+R_{0}\right) \leq I \cdot\left(1+R_{\text {liq }}\right), \\
C \geq 0 .
\end{gathered}
$$

The target function $Z$ is equal to the value of discounted expected value of future dividends. In period 1 , the manager has to determine $C$, while her task in period 2 is to fix the values for $B$ and $I$. As a consequence, both $B$ and $I$ might be depending on the former decision regarding $C$ and the resulting state of nature as described by realized cash flows $\tilde{c}$ out of assets in place. Therefore we have to write $I(\tilde{c}, C)$ and $B(\tilde{c}, C)$. Moreover, let $U_{A}$ denote the utility out of the uncertain investment returns for an ambiguity averse investor. We model ambiguity aversion similar to Klibanoff et al. (2005), who calculate first the certainty equivalent for an uncertain probability set $\Delta$, the possible probabilities over $S$. Consequently, this certainty equivalent for $\Delta$ is used to compute expected utility according to one's risk preferences. Formally, their smooth ambiguity model has the following representation:

$$
U_{A}(g(I))=\int_{\Delta} \Phi\left(\int_{S} u(g(I)) d \pi\right) d \mu .
$$

We assume that investors are risk neutral so that: $\int_{S} u(g(I)) d \pi=E(g(I(\tilde{c}, C), \tilde{\varepsilon}))$. Such a (simplifying) assumption is justified if investors diversify away risk to large extent on efficient capital markets. In fact, one essential difference between risk and ambiguity features is that uncertainty cannot be diversified away, but risk can (at least the unsystematic risk can) (Epstein and Schneider, 2008; Epstein and Schneider, 2010). We will return to this issue in our empirical section.

In addition, we further simplify equation (6) by assuming that the decision maker displays a constant ambiguity aversion which requires $\int_{\Delta} \Phi(x)=-\frac{1}{\delta} \cdot e^{-\delta \cdot x}$. Hence, with in- 
creasing $\delta$, the decision maker becomes more ambiguity averse and uncertain returns from investments are valued less favorably. These assumptions enable us to rewrite the ambiguity utility $U_{A}(g(I(\tilde{c}, C)))$ by simply introducing an ambiguity factor $f(\delta)<1$ as a decreasing function of an ambiguity aversion parameter $\delta\left(f^{\prime}(\delta)<0\right)$ :

$$
U_{A}(g(I(\tilde{c}, C)))=f(\delta) \cdot E(g(I(\tilde{c}, C), \tilde{\varepsilon}))
$$

As a consequence of assuming risk neutrality and no uncertainty with respect to future cash holdings $\tilde{c}$, there is no need for an ambiguity discount with respect to $I(\tilde{c}, C)$ and $\tilde{c}$. Therefore, in (2), we simply write $E(B(\tilde{c}, C)), E(I(\tilde{c}, C))$, and $E(\tilde{c})$.

Based on (2), it is easy to see that riskless borrowing has no direct impact on the overall objective function $Z$. Yet, in order to minimize the risk of forgoing profitable investment opportunities due to limited funds, a manager is going to draw on the entire credit line that is granted to her company. Due to this indirect relation, $Z$ is monotonously increasing in $B$. Thus, the inequality (4) of our model is binding with an optimal value $B_{\text {opt }}$ of $B$ according to $B_{o p t}=I \cdot\left(1+R_{\text {liq }}\right) /\left(1+R_{0}\right)$

This is going to simplify the problem at hand, since at the beginning of period 2, we just have to maximize the objective function with respect to $I$. In states of high cash flow $(c)$, where the (first-best) optimal investment program $I^{*}$ is feasible, we have:

$$
f(\delta) \cdot E\left(g^{\prime}(I(c, C), \tilde{\varepsilon})\right)=1+R_{0} .
$$

It might be possible that we have $B_{o p t}+c+C>I^{*}$, because of very high cash flows c. In this situation, excess cash $I^{*}-B_{o p t}-c-C$ is paid out as dividends in period 2. Assuming that the second derivative of the investment yield function is negative, equation (8) defines the optimal investment program, $I^{*}$. On the other hand, if the company is (ex-post, after period 1) financially constrained $\left(I^{*} \geq C+B_{\text {opt }}+c\right)$, it needs additional funds to finance the optimal 
investment program. In this scenario, the company is going to be able to invest more as cash holdings increase. Thus, the restriction $I \leq C+B_{o p t}+c$ is binding and the resulting investment is equal to:

$$
I_{\text {con }}=\frac{(C+c) \cdot\left(1+R_{0}\right)}{R_{0}-R_{\text {liq }}}
$$

Hence, the investment program depends on cash holdings for financially constrained firms, but is completely detached from cash holdings in firms where the optimal investment program can be implemented regardless of cash holdings. This ex-post solution after period 1 molds the cash holding policy at the beginning of period 1 .

Let $I_{\text {opt }}$ stand for the state-dependent optimal investment. With $h(c)$ being the density function of $\tilde{c}$, we can rewrite the objective function (2):

$$
Z\left(C, I_{\text {opt }}, B_{\text {opt }}\right)=X-C+\int_{I^{*}-B_{o p t}-C}^{\infty}\left[\frac{C}{1+R_{0}}+\frac{\tilde{c}}{1+R_{0}}-\frac{I^{*}}{1+R_{0}}+\frac{I^{*}\left(1+R_{\text {liq }}\right)}{\left(1+R_{0}\right)^{2}}+\right.
$$

$$
\begin{aligned}
& \left.\frac{f(\delta) \cdot E\left(g\left(I^{*}, \tilde{\varepsilon}\right)\right)}{\left(1+R_{0}\right)^{2}}-\frac{I^{*} \cdot\left(1+R_{l i q}\right)}{\left(1+R_{0}\right)^{2}}\right] \cdot h(c) d c+ \\
& \int_{0}^{I^{*}-B_{o p t}-C}\left[\frac{f(\delta) \cdot E\left(g\left(I_{\text {con }}(c, C), \tilde{\varepsilon}\right)\right)}{\left(1+R_{0}\right)^{2}}-\frac{I_{c o n}(c, C) \cdot\left(1+R_{l i q}\right)}{\left(1+R_{0}\right)^{2}}\right] \cdot h(c) d c .
\end{aligned}
$$

It should be noticed that $I_{c o n}$ - as seen from period 1 - is a random variable as well due to its dependence on $c$. Based on $Z\left(C, I_{o p t}, B_{o p t}\right)$, the first-order necessary condition for optimal cash holding runs

$$
\begin{aligned}
& G(C, \delta):=\frac{d Z\left(C, I_{\text {opt }}, B_{o p t}\right)}{d C}=-1+\int_{I^{*}-B_{o p t}-C}^{\infty}\left[\frac{1}{1+R_{0}}\right] \cdot h(c) d c+\left(\frac{f(\delta) \cdot E\left(g\left(I^{*}, \tilde{\varepsilon}\right)\right)}{\left(1+R_{0}\right)^{2}}-\frac{I^{*} \cdot\left(1+R_{l i q}\right)}{\left(1+R_{0}\right)^{2}}\right)+ \\
& \int_{0}^{I^{*}-B_{o p t}-C}\left[\frac{f(\delta) \cdot E\left(g r\left(I_{\text {con }}(c, C), \tilde{\varepsilon}\right)\right)-\left(1+R_{l i q}\right)}{\left(R_{0}-R_{l i q}\right) \cdot\left(1+R_{0}\right)}\right] \cdot h(c) d c-\left(\frac{f(\delta) \cdot E\left(g\left(I^{*}, \tilde{s}\right)\right)}{\left(1+R_{0}\right)^{2}}-\frac{I^{*} \cdot\left(1+R_{l i q}\right)}{\left(1+R_{0}\right)^{2}}\right)=0
\end{aligned}
$$

In a situation with $I^{*} \leq B_{o p t}+c_{\text {min }}$, i.e., even without cash holdings no danger of a binding financial constraint (note that we assume that $c$ as well as $C$ can only take non- 
negative values), we have $\int_{I^{*}-B_{o p t}-C}^{\infty} h(c) d c=1$ and $\int_{0}^{I^{*}-B_{o p t}-C} h(c) d c=0$. In this case, the derivative $\partial Z\left(C, I_{o p t}, B_{o p t}\right) / \partial C$ is equal to $-1+1 /\left(1+R_{0}\right)<0$, which directly implies $C_{o p t}=$ 0 due to (5). Apparently, in such a setting, ambiguity aversion does not influence the marginal utility contribution of cash holdings which is always negative, as $I=I^{*}$ is possible even for $C$ $=0$.

However, cash holdings may also serve other purposes. For instance, cash holdings can finance daily operations, which help companies avoid transaction costs of short-term external financing. Hence, optimal cash holding levels are not going to be zero even for financially unconstrained companies, as we demonstrate in the empirical section. Yet, these transaction costs are not afflicted with uncertainty, as they have short-term effects. Consequently, in such settings with exogenous reasons for cash holdings as transaction costs, the marginal utility contribution and the optimal value $C_{o p t}$ would be independent of the magnitude of ambiguity. In other words, ambiguity preferences are irrelevant for the cash management policy for financially unconstrained companies, as we show below.

For financially constrained firms, i.e. $\int_{0}^{I^{*}-B_{o p t}-C} h(c) d c>0$, the choice $C=0$ does not necessarily have to be optimal even if we ignore transaction costs or other advantages of cash holdings. Cash holdings are more valuable, if a company is financially constrained according to our model and potentially positive, as it is evident in (11). This follows from the fact that $\frac{f(\delta) \cdot E\left(g^{\prime}\left(I_{\text {con }}(c, C), \tilde{\varepsilon}\right)\right)-\left(1+R_{\text {liq }}\right)}{\left(R_{0}-R_{l i q}\right) \cdot\left(1+R_{0}\right)}>\frac{1}{\left(1+R_{0}\right)}$, since $f(\delta) \cdot E\left(g^{\prime}\left(I_{c o n}(c, C), \tilde{\varepsilon}\right)\right)>1+R_{0}$ for every $I_{c o n}<I^{*}$. This implies that companies facing financial constraints have more valuable investment opportunities. This is logical as these companies cannot implement all profitable investment projects and the second derivative of investment return function, $g^{\prime \prime}\left(I_{c o n}(c, C), \tilde{\varepsilon}\right)$ is negative. As a result, cash holdings are increasingly valuable as the probability of being 
financially constrained $\left(\int_{0}^{I^{*}-B_{o p t}-C} h(c) d c\right)$ increases. This result of our model is also in line with the empirical findings regarding marginal expected gross returns of cash holdings of financially constrained firms (Denis and Sibikov, 2010). This conclusion of our model is also in line with the findings of empirical studies such as Opler et al. (1999), Pinkowitz and Williamson (2007), and Bates et al. (2009) that argue that companies with better growth opportunities are going to hold more cash.

In particular, we are interested in the influence of varying degrees of ambiguity aversion on the marginal utility contribution of cash: $\partial^{2} Z / \partial C \partial \delta$. We therefore just need to study how $G$ is related to $\delta$, thus we determine $\partial G / \partial \delta$ :

$$
\frac{\partial G(C, \delta)}{\partial \delta}=f^{\prime}(\delta) \cdot \int_{0}^{I^{*}-B_{o p t}-C}\left[\frac{E\left(g^{\prime}\left(I_{\text {con }}(c, C), \tilde{\varepsilon}\right)\right)}{\left(R_{0}-R_{\text {liq }}\right) \cdot\left(1+R_{0}\right)}\right] \cdot h(c) d c<0
$$

The sign of this derivative is negative, as $f^{\prime}(\delta)<0$. The intuition behind (12) is very simple. Clearly, with cash holdings, firms are going to be able to implement value-increasing investments in the future even at times when they cannot turn to external credit markets for financing purposes. This might increase the value of the company to a certain extent despite the opportunity costs of cash holdings that are equal to $-1+1 /\left(1+R_{0}\right)$. However, with increasing ambiguity aversion, uncertain investments are less valuable for investors and, as a consequence, cash holdings become (relatively) superfluous. At the same time, this relation between ambiguity aversion and value of cash is only apparent for firms that face financial constraints, i.e. if $\int_{0}^{I^{*}-B_{o p t}-C} h(c) d c>0$. Summarizing, our formal analysis implies that ambiguity aversion determines the marginal utility contribution of cash holdings for financially constrained firms, but not for financially unconstrained firms.

Based on these results, we can also calculate the connection between ambiguity aversion $(\delta)$ and the level of optimal cash holdings, $C_{o p t}$. We abstract from managerial entrench- 
ment problem and assume that managers' interests are aligned with the interests of their investors. In other words, we assume that the managers have the same target function $Z$, as their investors. In this case, because of $\partial C_{o p t} / \partial \delta=-\frac{\partial q\left(c_{o p t}, \delta\right)}{\partial \delta} / \frac{\partial q\left(c_{o p t}, \delta\right)}{\partial C_{o p t}}$, we immediately get $\partial C_{o p t} / \partial \delta<0$ combining the negative sign of (12) and $\frac{\partial G\left(C_{o p t}, \delta\right)}{\partial C_{o p t}}<0$, which simply describes the sufficient condition for an inner solution $C_{\text {opt }}$. This means that optimal level of cash holdings are decreasing with the level of ambiguity aversion, but this is only true if $\frac{\partial G\left(C_{o p t}, \delta\right)}{\partial \delta}<0$, i.e., for financially constrained companies. This gives rise to the following four hypotheses.

\section{Hypothesis 1a:}

With increasing ambiguity aversion of investors, the market value contribution of cash holdings decreases for financially constrained firms.

\section{Hypothesis 1b:}

For financially unconstrained firms, the market value contribution of cash holdings is not related to the magnitude of investor's ambiguity aversion.

\section{Hypothesis 2a:}

The optimal amount of cash holding decreases for financially constrained firms with ambiguity aversion of investors. 


\section{Hypothesis 2b:}

For financially unconstrained firms, the optimal amount of cash holdings is independent of the magnitude of investor's ambiguity aversion.

\section{Empirical Analysis}

After presenting our theoretical model, we want to investigate its implications empirically in the next section. It should be noted that we expect Hypotheses $1 \mathrm{a}$ and $1 \mathrm{~b}$ to be more strongly confirmed than Hypotheses $2 \mathrm{a}$ and $2 \mathrm{~b}$, because firm valuation is directly related to investor preferences, but for Hypotheses $2 \mathrm{a}$ and $2 \mathrm{~b}$ to hold we also need the assumption that managers act according to investor preferences - and we know from the literature discussed above that managerial behavior may also be driven by egoistic motives. Keeping this in mind, we first explain our dataset and then illustrate our regression approach. Lastly, we discuss our results.

\subsection{Data}

\subsubsection{Ambiguity Aversion}

The main variable of interest in our study is the preference parameter ambiguity aversion. We have obtained this parameter via the international test of risk attitudes (INTRA) survey that is carried out mainly between 2005 and 2009 among undergraduate students of economics in 46 countries. Overall, 6,000 university students have participated, as we requested from each participant to complete a questionnaire that included questions on risk and time preferences, cultural attitudes, and some personal information (Wang et al., 2010; Rieger et al., 2011).

We have elicited average ambiguity aversion of participants in each country based on the answers to the well-known Ellsberg's urn game where participants can choose between an uncertain lottery with an unknown probability of winning and a risky lottery with a winning probability less than $50 \%$ (for the same potential payoff). Investing in the risky rather than 
the uncertain lottery indicates ambiguity aversion, the unease resulting from dealing with unknown probability distributions, i.e. a concave function, $\Phi$ (Rieger and Wang, 2012).

In what follows, we utilize elicited preferences in these choice tasks as proxies for preference patterns of the whole population in the respective countries. This might be subject to some critique, since this approach implicitly assumes that our student sample is representative for the whole population in a country. Clearly, students are younger and less experienced compared to the rest of the society and this may cast doubt on the representative quality of our sample. Yet, in different areas of experimental economics, there is enough evidence revealing similarities between average investor preferences in a society and students' preferences (King et al., 1993). Moreover, since we are conducting a cross-country empirical comparison, what really matters is the difference between the preferences located in different countries and there is no reason to believe that cross-country differences in ambiguity aversion should be distributed differently for students compared to the general population.

Furthermore, despite globalization, our empirical analysis emanates from the assumption that only preferences of domestic investors count for the valuation of cash. Although this assumption seems to be very restrictive, many empirical studies document a very strong home bias, i.e., a tendency to invest in stocks listed in domestic stock markets (see Lau et al., 2010). For this reason, we think it is acceptable to work with country specific investor preference parameters, since even the shares of large companies in open markets are mostly held by local investors. Still, in Section 4, we are going to discuss whether our results become less clear with an increasing proportion of foreign ownership.

\subsubsection{Data on Other Dependent and Independent Variables}

Data regarding company information including annual returns, cash holdings, and other control variables are extracted from Datastream, a service of Thomson Reuters. We have chosen to analyze all the companies listed under the constituent list "World Market" provided by Datastream consisting of 6,922 companies from 59 countries. Cross matching this sample 
with the countries for which we have data for ambiguity aversion leaves us with 3,059 companies from 29 countries. We find this sample much better suited for our purposes than the Compustat Global Data, since Compustat Global Data are dominated by companies located in the United States, especially in the early years. Our sample is much more balanced across different countries. We discuss this issue further in the next sections.

Our analyses cover all the firm years between 1992 and 2011, since the global benchmark portfolio returns formed on size and market-to-book ratio are only available for this 20 year period in the data library of Kenneth French, which we use in order to calculate the excess returns required to analyze the first hypothesis. We omit all financial and utility companies from our analysis (four digit SIC classification numbers between 6000-6999 and 49004949, respectively), since these firms are mostly regulated and should have a small differential between the cost of internal and external funds.

\subsection{Regression Models}

We have two hypotheses which require two different empirical analyses. In the first regression model, we examine the impact of ambiguity aversion on the valuation of cash holdings distinguishing between financially constrained and unconstrained firms. In the second empirical model, we investigate the impact of ambiguity aversion on the amount of cash holdings again separately for financially constrained and unconstrained firms.

\subsubsection{First Hypothesis: Valuation Effects of Cash Holdings}

We start discussing our empirical analysis concerning the first hypothesis. Generally, we can distinguish between two types of empirical methods investigating the value of cash. The first one goes back to Fama and French (1998) and many papers including Pinkowitz et al. (2006) and Pinkowitz and Williamson (2007) used this method to analyze how the market value of a company (divided by total assets) is related to cash holdings or changes in cash holdings. However, we prefer another approach applied by Faulkender and Wang (2006) for 
two reasons (see also Denis and Sibikov, 2010). First of all, Fama and French (1998) did not consider time-varying sensitivities to risk factors, i.e. changes in discount rates over time. Faulkender and Wang (2006) address this problem by correcting stock returns with the help of benchmark returns. Secondly, the market-to-book ratio is not comparable across different companies especially across different countries due to different accounting conventions and methods. On the other hand, yearly returns of listed companies are defined identically in every country and for each company.

Hence, we conduct linear regressions of excess returns of the companies in our sample on ambiguity aversion with robust standard errors clustered by firm. We control for several other factors such as leverage, net financing, and change in R\&D expenditures and in dividends according to the methodology of Faulkender and Wang (2006) and Denis and Sibikov (2010). All firm-specific control variables and independent variables are winsorized at $1 \%$ level and all control variables are also deflated by the lagged market value of equity except for leverage.

Moreover, we use the common law dummy (La Porta et al., 1998), a corruption perception index (provided by Transparency International), the annual inflation rate and total taxes (Djankov et al., 2010) as additional country-specific control variables. In contrast to our firm-specific data, country-specific data (except the annual inflation rate) including our ambiguity aversion parameter are not given as panel data. However, we assume that countryspecific characteristics change only relatively slowly across time so that we are allowed to work with given country-specific data over the whole observation period from 1992 to 2011. For example, a corresponding assumption typically also underlies cross-country analyses of cash holdings that are based on cultural features (Chen et al., 2013) or governance structures (Dittmar et al., 2003). We elaborate on this potential problem further in our robustness analysis. We also utilize year dummies and industry dummies based on two-digit SIC codes. 
Since we analyze companies from 29 different countries, we take the global benchmark portfolios from the database of Kenneth French as our index. Thus, we define the excess return as the difference between the annual stock return and the matching global benchmark portfolio return formed on size and market-to-book ratio. Although we do not report them here, the results are not much different if we run regressions of the excess returns (annual company return minus risk free return) on the factors of Fama and French's three factor model (market index return, size and market-to-book ratio) with the same set of control variables. Including momentum as the fourth risk factor does not affect our results either. Table I gives an overview of descriptive statistics with respect to all variables in our regressions.

$>$ Insert Table I

\subsubsection{Second Hypothesis: The Amount of Optimal Cash Holding}

In order to analyze the second hypothesis regarding the relation between cash holdings and ambiguity aversion, we use a similar empirical model as Opler et al. (1999), since this is the most-renowned method for the analysis of cash holdings policies of a company. The dependent variable in all regressions is cash holdings divided by total assets minus cash holdings (Cash/NetAssets). Since we cannot have negative cash values; we use a Tobit model with the lower bound set equal to zero to account for the non-normal distribution of our dependent variable. Robust standard errors are again clustered at firm-level and like in the first model we use year dummies and industry dummies.

As we perform a cross-country analysis, we again add some country specific legal variables in our regression model similar to the empirical model of Dittmar et al. (2003) and to the empirical model of the previous section such as the common law dummy, inflation, corruption, and total taxes besides the usual set of company-specific control variables of previous empirical models based on Opler et al. (1999). Table II gives an overview of descriptive statistics with respect to new variables in the second regression model. 
>> Insert Table II

\subsection{Results}

Our model conjectures that ambiguity aversion should only be relevant if the likelihood of experiencing financial difficulties is high. In order to investigate this hypothesis, we divide our dataset into two subsets. One group consists of (relatively) financially constrained firms and the other one includes (relatively) unconstrained firms. We define the level of financial constraints based on three different proxies, which we discuss below.

The investigation of the first hypothesis requires us to compare the impact of ambiguity aversion on the valuation of cash for these two groups. For this purpose, we have to generate an interaction term between changes in cash and the ambiguity aversion parameter. We center both parameters to avoid multicollinearity problems regarding this interaction term. We predict a negative estimator for this interaction term for financially constrained firms which would imply in line with Hypothesis 1a) that changes in cash holdings lead to lower excess returns if ambiguity aversion is high. According to our Hypothesis 1b), this interaction term should be insignificant for financially unconstrained firms.

In order to analyze our second hypothesis, we again divide our sample into two groups based on the level of financial constraints faced by a firm. We predict that ambiguity aversion is negatively correlated with cash holdings only for financially constrained firms and it is uncorrelated with cash holdings for unconstrained firms.

The literature has discussed several possibilities to identify the level of financial constraints faced by firms. However, there is no general consensus on a single measure. Therefore, like other researchers before us, we are also going to rely on multiple proxies to distinguish between financially constrained and unconstrained firms (see also Almeida et al., 2004). 
Dividend payout ratio: Fazzari et al. (1988) argue that unconstrained firms are likely to have higher payout ratios, while constrained firms prefer to reduce dividend ratios. Our model also yields a similar prediction, as (ex-post) constrained firms are not going to pay dividends in period $\mathrm{t}=1$ according to our model. Hence, we assign all firms with a lower than median dividend payout ratio to the group of financially constrained firms and we refer to companies with above-median dividend payout ratios as financially unconstrained companies. Dividend payout ratio is defined as the ratio of cash dividends divided by total assets.

Company size: Diamond and Verrecchia (1991) posit that large firms benefit more from sharing information and, consequently, they suffer less from problems related to informational asymmetry. In our model, this is captured by increased borrowing possibilities $(B)$ or a higher $R_{\text {liq }}$, which reduces the probability that a firm is unable to put the optimal investment program in practice. In other words, large firms need relatively less cash holdings, since they have easier access to outside funding (Fazzari et al., 1988). All figures for total assets are inflation-adjusted and in constant 1992 dollars and we divide our sample based on median company size into two groups.

Company age: Some researchers have also originated indices to measure the degree of financial constraints faced by a company by weighting different factors including company size and dividend payments. In a recent study, Hadlock and Pierce (2012) recommend that researchers rely solely on firm size and age, two relatively exogenous firm characteristics, to identify constrained firms instead of using measures such as the Kaplan and Zingales (Kaplan and Zingales, 1997; Lamont et al., 2001) or the Whited and Wu Index (Whited and Wu, 2006). Leaning on this paper, we use company age as another proxy to distinguish between financially constrained and unconstrained firms. Again, we divide our data sample into two groups based on the median score for company age. 
In all three cases, we generate a constraint dummy, which assumes the value 1 for all firm-years with higher likelihood facing financial constraints and we assign the value 0 for the other firm-years. For all three financial constraint dummies, we find that the interaction between changes in cash and ambiguity aversion, $\Delta C_{t} \times$ Ambiguity Aversion is significantly negative and only for the subset of financially constrained firms. For financially unconstrained firms, ambiguity aversion is not related to the valuation of cash holdings. Furthermore, we observe that both cash holdings $\left(C_{t}\right)$ and changes in cash holdings $\left(\Delta C_{t}\right)$ are valued more favorably for financially constrained firms, as evident by the larger coefficients and higher significance levels. Thus, these results are also in line with the findings of earlier studies of Faulkender and Wang (2006) and Denis and Sibikov (2010). At the same time, all control variables except net financing $\left(N F_{t}\right)$ are significant in our model with the same signs as previous empirical studies by Faulkender and Wang (2006) and Denis and Sibikov (2010), although we use a different sample of companies from 29 different countries. This demonstrates that the results of previous empirical studies investigating only US companies are also valid internationally.

\section{$>>$ Insert Table III}

The regressions analyzing our second hypothesis demonstrate also that Ambiguity Aversion is negatively significant for the subsample of financially constrained firms. Other control variables taken from the study of Opler et al. (1999) are also significant with the signs in agreement with this work. Hence, in line with Hypotheses $2 a$ and $2 b$, we found that managers anticipate investors' preferences regarding cash holdings and adjust the cash policy accordingly. On the other hand, for financially constrained firms, the correlation between cash holdings and Ambiguity Aversion is most of the time insignificant as we predicted. Although Hypotheses $2 \mathrm{a}$ and $2 \mathrm{~b}$ rely on the additional assumption of managers acting in the interest of shareholders, there is quite strong evidence for both hypotheses to hold as well. Yet, we ob- 
serve in one case that cash holdings are positively correlated with ambiguity aversion for financially unconstrained firms. This result also implies that managers have another agenda and they do not simply try to maximize company value. Still, the strong negative correlation in the sample consisting of constrained firms suggests that the catering motive is dominant.

>> Insert Table IV

\section{Discussion}

After confirming our main hypotheses, we would like to discuss some further implications of our theory. First, we elaborate on the main assumption of our model, a strong home bias effect. Secondly, in our model, we have assumed risk neutrality (or perfect risk diversification) and ambiguity aversion. However, risk aversion combined with ambiguity neutrality would also lead to the same conclusions and to the same results in our formal set-up. Therefore, we analyze whether risk aversion or ambiguity aversion is the actual decisive factor for our results. Thirdly, we question whether the proneness to ambiguity aversion and its impact on cash policies are not time-varying. Last but not least, we would also like to control for cultural factors in order to address concerns that these cultural dimensions capture the same aspects of human decision preferences as our newly elicited behavioral parameter.

\subsection{Foreign Ownership and the Relationship between Cash and Ambiguity Aversion}

As we mentioned in Section 2, our model assumes implicitly that only local investors' preferences are vital for the market reaction to liquidity management. Several papers have demonstrated that indeed a very large portion of companies is owned by domestic investors even in free market economies. Now, we analyze how our results are affected by an increasing foreign ownership share in the company. For this purpose, we use data on Foreign Ownership, which is defined in Datastream as the percentage of strategic share holdings of $5 \%$ or more held in a country outside that of the issuer. 
We divide our firm-year observations into two groups. The first group consists of firm-years where Foreign Ownership is higher than $30 \%$. The second subsample includes all other the firm-years. After that, we run the regressions in Section 3 for both subsamples and observe that the relation between the value of cash and ambiguity aversion is only strong for the financially constrained companies of the second subsample. Changing the cutoff level for the Foreign Ownership has no impact on our results, as the interaction between ambiguity aversion and changes in cash remain insignificant for the subsample controlled by foreign owners even when we assign firm-years with a Foreign Ownership higher than $40 \%$ or 50\% to this subsample. We report here only the results for the subsample consisting of foreign controlled firms, as the results for the other subsample is basically the same as in Table III, since most of the firms are controlled by domestic investors. This also shows that our assumption regarding the magnitude of the home bias effect is not very critical, as shown in different studies.

\section{>> Insert Table V}

After that, we repeat the same comparing analysis for the second regression model as well. We find again that cash holdings are most of the time not related to the country-specific ambiguity aversion measure either for constrained or unconstrained firms. There is a negative correlation between cash holdings and ambiguity aversion only if financially constraints are defined according to company age. Furthermore, this negative relationship disappears if we define the cutoff level for Foreign Ownership as $50 \%$. In the other two cases, there is no relation between cash holdings and ambiguity aversion for financially constrained firms consistent with our model predictions.

\section{>> Insert Table VI}

Hence, we conclude that our local investor preference parameter for ambiguity aversion is decisive for the market valuation of cash and the optimal amount of cash holdings only 
if the company is controlled by local investors. This circumstantiates the validity of our theory and also addresses concerns regarding the representativeness of our student sample for the whole population: Students' preferences work well as a proxy for overall preferences only when we expect them to do so.

\subsection{Risk Aversion or Ambiguity Aversion}

In Section 2, we emanated from risk neutral and ambiguity averse investors. At the same time, it is clear that our model yields exactly the same predictions if we assume risk averse and ambiguity neutral investors. Of course, we use our preference parameter for ambiguity aversion in the regressions; hence our assumption regarding ambiguity aversion seems to hold.

Yet, risk aversion can also have an impact on the value of cash together with ambiguity aversion, if investors are both risk and ambiguity averse. Still, we have ignored the possible relevance of risk preferences until now arguing that investors have diversified unsystematic risk away to a very large extent, i.e. the relevance of risk preferences for subjective valuation and optimization is limited in comparison to the importance of ambiguity aspects. Now, we want to put this assumption into test by investigating the impact of risk aversion on the value of cash and its optimal amount by using a preference parameter for risk aversion that we have obtained in our INTRA survey as well.

Similarly to the preference parameter for ambiguity aversion, risk aversion is also elicited in our survey this time with the help of a matching task. Participants had to declare the minimum amount of certainty equivalent for which they are indifferent between this certainty equivalent and a lottery with a $50 \%$ probability of winning some money. To each country, we have assigned a score for risk aversion depending on the average amount of the certainty equivalent, which we refer to as Risk Aversion in our regressions. 
Now, we add Risk Aversion and its interaction with changes in cash $\left(\Delta C_{t} \times\right.$ Risk Aversion) as an additional variable in the regression models of Section 3. We only report the results concerning the main variables of interest, as the addition of the new interaction term $\Delta C_{t} \times$ Risk Aversion does not change the results with regard to the other control variables.

We observe no systematically significant correlation between this interaction term and excess returns defined as in Section 3 neither for financially constrained companies nor for unconstrained ones. On the other hand, the interaction term $\Delta C_{t} \times$ Ambiguity Aversion remains to be significant and negative and it is only significant for financially constrained firms even after including the parameter for Risk Aversion. Hence, we can conclude that our results in Table III can be traced back to ambiguity preferences and our assumption regarding the irrelevance of risk preferences seems to hold.

\section{$>>$ Insert Table VII}

We perform a similar robustness check for the second regression model as well. Analogously, we add Risk Aversion into the second regression model as an additional variable and run our regressions from Table IV one more time. Once again, there is no consistent evidence of a negative relationship between Risk Aversion and cash holdings for financially constrained firms while this kind of relationship is confirmed with respect to Ambiguity Aversion for each financial constraint proxy. Thus, for unconstrained companies, Ambiguity Aversion is the only preference pattern that shapes the pattern of cash holdings, which is consistent with our model. Yet, we also have to admit that the results are somewhat less consistent with our predictions here, as we observe a positive relation between both Ambiguity Aversion and Risk Aversion and cash holdings for unconstrained firms in two out of three regressions. However, as we mentioned above, this is understandable, since managers have other incentives than shareholders and this can lead to excess cash holdings and this can be related to Ambiguity Aver- 
sion or Risk Aversion. We are not going to discuss this issue further in this paper, as it is beyond its scope.

>> Insert Table VIII

\subsection{Market cycles and cash policies}

Another assumption underlying our empirical analysis is the steady impact of ambiguity aversion on cash policies. We argue that country-specific characteristics change only relatively slowly across time so that we are allowed to work with constant country-specific data over the whole observation period. Although this is a very common assumption underlying empirical models analyzing cross-country impact of corporate governance or cultural models in panel data, readers might still doubt its validity.

Either the preference parameters might be time-varying or their impact on cash policy might be changing over time. In order to mitigate these doubts, we compare the relevance of ambiguity aversion for cash policy decisions before and since the 2008 global financial crisis and find that our results in both Table III and Table IV can be confirmed in both observation periods. Consistent with our assumption, proneness to ambiguity aversion seems to be persistent over time and does not depend on the macroeconomic environment.

\subsection{Cultural explanation of cash holdings}

According to our results so far, ambiguity aversion seems to be related to cash holding policies. However, as has been mentioned in the paper, another approach has emerged recently to explain cross-country differences in financial practices in corporations and there might be concerns regarding the similarities between cultural parameters and our preference parameters. Hence, we want to understand, whether these two dimensions capture the same aspects of preference patterns of human beings. 
In order to achieve that, we extend the empirical analysis in the previous section and analyze behavioral and cultural factors combined in a single empirical model. The papers of Ramirez and Tadesse (2009) and Chen et al. (2013) discuss the relevance of cultural aspects for cash holding decisions on the basis of cultural dimensions defined by Hofstede (2001). These papers reveal a positive (negative) correlation between cultural dimension Uncertainty Avoidance (Individualism) and cash holdings in a company.

Now, we add these cultural parameters to our regressions from Table IV as additional controls and control how our results look in this additional robustness test. The results clearly support the previous empirical findings regarding these cultural dimensions even after adding Ambiguity Aversion. We do not distinguish in our Table IX between financially constrained and unconstrained firms since the impact of these cultural dimensions on cash holdings is not related to precautionary motive of cash holdings. Therefore, it is not surprising to see that these cultural dimensions are impactful on cash holdings for both types of firms. Hence, we only report the results for the whole subsample. Our behavioral parameter for Ambiguity Aversion is again only significant for financially constrained forms, although the results are not reported here.

\section{>> Insert Table IX}

To sum up, we observe that our behavioral preference parameters cover new grounds that have not been addressed before by cultural models. For instance, Uncertainty Avoidance is argued to be related to managers' fear of undesired states of nature. With increasing Uncertainty Avoidance, they prefer to hedge more against these risks. On the other hand, individualistic managers believe to have an easier access to external capital markets and therefore they do not have the urge to hold cash. Hence, cultural dimensions rather capture different aspects of the human decision process and should be considered together with behavioral parameters in order to understand investors' preferences completely. In this sense, our behavioral pa- 
rameters can coexist with cultural models and as a result, our behavioral variables remain important determinants of financial practices of corporations even after controlling for cultural dimensions.

Furthermore, cultural values and dimensions are very complex structures and they are very hard to interpret from an economical point of view. It is by no means clear how different cultural dimensions enter economic decision problems. For instance, Fidrmuc and Jacob (2010) recognize this problem, as they conjecture that UAI may affect dividend payouts in two opposing ways. Here, we think, lies a clear advantage of our behavioral approach, as we can derive clear predictions on solid economic grounds.

\section{Conclusion}

To recap, our paper provides the first theoretical and empirical analysis discussing the potential relevance of investor preferences for the value of cash and cash holding policies. Our empirical evidence suggests that cash is valued less favorably by ambiguity averse investors of financially constrained firms. On the other hand, if insuring a firm against the future illiquidity problem is not value increasing, i.e., a company is financially unconstrained, ambiguity aversion is not related to the value of cash. For the same reasons, ambiguity aversion is related to the amount of cash holdings only for financially constrained firms implying that managers are not only aware of investors' preferences, but they also cater to these needs.

Summing up, our paper is the first one to analyze the connection between boundedly rational investor preferences and corporate cash policies. We develop a theoretical framework that can integrate investors' preferences and catering motives in the cash management process investigating both the valuation of cash and aggregate cash demand of a company from this perspective. Furthermore, unlike previous empirical studies with similar scope (mostly con- 
cerning dividend policies), our empirical work provides a straightforward test regarding the link between behavioral biases and cash management. 


\section{References}

Acharya, V., Almeida, H., Campello, M., (2007) Is cash negative debt? A hedging perspective on corporate financial policies, Journal of Financial Intermediation 16, 515-554.

Almeida, H., Campello, M., Weisbach, M. S. (2004) The cash flow sensitivity of cash, Journal of Finance 59, 1777-1804.

Baker, M., Greenwood, R., Wurgler, J. (2009) Catering through nominal share prices, Journal of Finance 64, 2559-2590.

Baker, M., Wurgler, J. (2004) A catering theory of dividends, Journal of Finance 59, 11251165.

Bates, T. W., Kahle, K. M., Stulz, R. M. (2009) Why do US firms hold so much more cash than they used to? Journal of Finance 64, 1985-2021.

Becker, B., Ivkociv, Z., and Weisbenner, S. (2011) Local dividend clienteles, Journal of Finance 66, 655-684.

Bouwman, C., Fuller, K., Nain, A., 2009. Market valuation and acquisition quality: empirical evidence. Review of Financial Studies 22, 633-679.

Breuer, W., Rieger, M. O., Soypak, K. C. (2013) The behavioral foundations of corporate dividend policy: a Cross-Country Analysis. Working Paper.

Chen, Y., Dou, P.Y., Rhee, S.G., Truong, C., Veeraraghavan, M. (2013) National Culture and Corporate Cash Holdings around the World. Working Paper.

Denis, J. D., Sibikov, V. (2010). Financial constraints, investment, and the value of cash holding. Review of Financial Studies 23, 247-269.

Diamond, D. W., Verrecchia, R. E. (1991) Disclosure, liquidity, and the cost of capital, Journal of Finance 46, 1325-1359.

Dittmar, A., Mahrt-Smith, J. (2007) Corporate governance and the value of cash holdings, Journal of Financial Economics 83, 599-634.

Dittmar, A., Mahrt-Smith, J., Servaes, H. (2003) International corporate governance and corporate cash holdings, Journal of Financial and Quantitative Analysis 38, 111-133.

Djankov, S., Ganser, T., McLiesh, C., Ramalho, R., Shleifer, A. (2010) The effect of corporate taxes on investment and entrepreneurship, American Economic Journal: Macroeconomics 2, 31-64.

Djankov, S., La Porta, R., Lopez-de-Silanes, F., Shleifer, A. (2008) The law and economics of self-dealing, Journal of Financial Economics 88, 430-465.

Fama, E. F., French, K. R. (1998) Taxes, financing decisions, and firm value, Journal of Finance 53, 819-843.

Faulkender, M., Wang, R. (2006) Corporate financial policy and the value of cash, Journal of Finance 61, 1957-1990.

Fazzari, S., Hubbard, R.G., Petersen, B. (1988) Financing constraints and corporate investment, Brooking Papers on Economic Activity 1, 141-195.

Fresard, L., Salva, C. (2010) The value of excess cash and corporate governance: evidence from US cross-listings, Journal of Financial Economics 98, 359-384.

Gompers, P., Ishii, J., Metrick, A. (2003) Corporate governance and equity prices, Quarterly Journal of Economics 118, 107-155.

Graham, J., Kumar, A. (2006) Do dividend clienteles exist? Evidence on dividend preferences of retail investors, Journal of Finance 61, 1305-1335.

Han, S., Qiu, J. (2007) Corporate precautionary cash holdings, Journal of Corporate Finance $13,43-57$.

Harford, J., (1999) Corporate cash reserves and acquisitions, Journal of Finance 54, 19691997.

Holmström, B., Tirole, J., (1998) Private and public supply of liquidity, Journal of Political Economy 106, 1-40. 
Jensen, M. C., (1986) Agency cost of free cash flow, corporate finance and takeovers, American Economic Review 76, 323-329.

Jensen, M.C., Meckling, W. H., (1976) Theory of the firm: managerial behavior, agency costs, and ownership structure. Journal of Financial Economics 3, 305-360.

Kahnemann, D., Tversky, A. (1979) Prospect theory: an analysis of decision under risk, Econometrica 47, 263-291.

Kaplan, S., Zingales, L. (1997) Do financing constraints explain why investment is correlated with cash flow? Quarterly Journal of Economics 112, 169-215.

Keynes, J.M. (1936) The General Theory of Employment, Interest and Money, McMillan, London.

King, R.R., Smith, V., Williams, A., Van Boening, M. (1993) The robustness of bubbles and crashes in experimental stock markets, in: Day, R., and Ping, C. (eds.), Nonlinear Dynamics and Evolutionary Economics, Oxford University Press, Oxford, pp. 183-200.

Klibanoff, P., Marinacci, M., Mukerji, S. (2005) A smooth model of decision making under ambiguity, Econometrica 73, 1849-1892.

Lamont, O., Polk, C., Saa-Requejo, J. (2001) Financial constraints and stock returns, Review of Financial Studies 14, 529-554.

Lins, K., Servaes, H., Tufano, P. (2010) What drives corporate liquidity? An international survey of cash holdings and lines of credit. Journal of Financial Economics 98, 160-176.

Myers, S.C., (1977) The determinants of corporate borrowing, Journal of Financial Economics $5,147-175$.

Opler, T., Pinkowitz, L., Stulz, R., Williamson, R. (1999) The determinants and implications of corporate cash holdings, Journal of Financial Economics, 52, 3-46.

Ozkan, A., Ozkan, N. (2004) Corporate cash holdings: an empirical investigation of UK companies, Journal of Banking and Finance 28, 2103-2134.

Pinkowitz, L., (2002) The market for corporate control and corporate cash holdings, Working Paper.

Pinkowitz, L., Stulz, R., Williamson, R. (2006) Does the contribution of corporate cash holdings and dividends to firm value depend on governance? A cross-country analysis, Journal of Finance 61, 2725-2751.

Pinkowitz, L., Williamson, R., (2007) What is the market value of a dollar of corporate cash? Journal of Applied Corporate Finance 19, 74-81.

Ramírez, A., Tadesse, S., (2009) Corporate cash holdings, uncertainty avoidance, and the multinationality of firms, International Business Review 18, 387-403.

Rieger, M.O., Wang, M., Hens, T. (2011) Prospect theory around the world, Working Paper.

Riger, M. O. and Wang, M. (2012) Can ambiguity aversion solve the equity premium puzzle? Survey evidence from international data, Finance Research Letters, 9, 63-72.

Wang, M., Rieger, M. O., Hens, T. (2010) How time preferences differ: evidence from 45 Countries, Working Paper.

Whited, T., Wu, G. (2006) Financial constraints risk. Review of Financial Studies 19, 531559. 


\section{Table I. Summary statistics}

This table presents the mean, standard deviation (STD), minimum (Min), maximum (Max) and number of observations $(\mathrm{N})$ for all the variables used in the first regression model. All variables except total debt to book value of assets $\left(L_{t}\right)$ and excess stock return are deflated by the lagged market value of equity. $\Delta E_{t}$ is the change in earnings before paid interests and taxes $(E B I T)$, and $\triangle N A_{t}$ is the change in total assets minus cash holdings. $\triangle R D_{t}$ represents the changes in $\mathrm{R} \& \mathrm{D}$ expenditures, which is set to zero if missing. $\Delta I_{t}$ is the yearly change in interest expense and $\Delta D_{t}$ is the change in total dividends. $N F_{t}$ is calculated as the total equity issuance minus repurchases plus debt issuance minus debt redemption. $\Delta C_{t}$ is the notation for the realized 1-year change in cash holdings. Dependent variables and firm-specific control variables are winsorized at the $1 \%$ level.

\begin{tabular}{|c|c|c|c|c|c|}
\hline Variable & Mean & STD & Min & $\operatorname{Max}$ & $\mathrm{N}$ \\
\hline Excess returns & 0.07 & 0.54 & -0.89 & 2.44 & 65,041 \\
\hline \multicolumn{6}{|c|}{ Company-Specific Control Variables } \\
\hline$\Delta E_{t}$ & 0.02 & 0.18 & -0.65 & 1.02 & 48,695 \\
\hline$\Delta N A_{t}$ & 0.09 & 0.54 & -1.93 & 3.46 & 49,240 \\
\hline$\Delta R D_{t}$ & 0.00 & 0.01 & -0.03 & 0.04 & 51,667 \\
\hline$\Delta I_{t}$ & 0.00 & 0.02 & -0.10 & 0.09 & 32,122 \\
\hline$\Delta D_{t}$ & 0.00 & 0.02 & -0.09 & 0.10 & 48,733 \\
\hline$N F_{t}$ & 0.01 & 0.32 & -1.07 & 2.91 & 56,996 \\
\hline$\Delta C_{t}$ & 0.02 & 0.15 & -0.54 & 0.86 & 49,328 \\
\hline$L_{t}$ & 23.35 & 17.93 & 0.00 & 79.51 & 74,351 \\
\hline$C_{t}$ & 0.25 & 0.39 & 0.00 & 2.88 & 67,262 \\
\hline \multicolumn{6}{|c|}{ Country-Specific Control Variables } \\
\hline Common Law Dummy & 0.46 & 0.50 & 0.00 & 1.00 & 79,926 \\
\hline Corruption & 7.09 & 1.80 & 0.00 & 9.40 & 79,926 \\
\hline Inflation & 0.03 & 0.18 & -0.08 & 7.50 & 75,520 \\
\hline Total Taxes & 47.28 & 11.22 & 24.35 & 107.38 & 79,926 \\
\hline \multicolumn{6}{|l|}{ Behavioral Variables } \\
\hline Ambiguity Aversion & 0.56 & 0.09 & 0.42 & 0.80 & 80,080 \\
\hline Uncertainty Avoidance & 61.72 & 25.18 & 0.00 & 112 & 79,200 \\
\hline
\end{tabular}


Table II. Summary statistics for second regression model

This table presents the mean, standard deviation (STD), minimum (Min), maximum (Max) and number of observations $(\mathrm{N})$ for all the company-specific control variables used in the second regression. We refrain from reporting the summary statistics for the variables that are included both in the first and second regression models. Real size is the value of total assets in constant 1992 dollars. The market-tobook ratio is measured as the market value of equity plus book value of debt divided by total assets $(M B$-Ratio $)$. Net working capital is calculated without cash before being divided by total assets (NWC/Assets). $L_{t}$ is total debt over total assets. $S G$ is the sales growth defined as net sales in year $t$ divided by net sales in year $t-1$. We also control for research and development (R\&D) spending and capital expenditures, denominated by net sales $(R \& D /$ Sales $)$ and total assets (Capex/Assets), respectively. Dividend Dummy assumes the value 1 (0) for company-years with above-median (below-median) levels for cash dividends to total assets. Cash flow is denominated by total book value of assets as well (CF/Assets). All variables listed in this table are winsorized at $1 \%$ level.

\begin{tabular}{|c|c|c|c|c|c|}
\hline Variable & Mean & STD & Min & Max & N \\
\hline Cash/NetAssets & 0.22 & 0.37 & 0.00 & 2.73 & 72,710 \\
\hline Company-Specific Control Variables & & & & & \\
\hline Real Size & 15.13 & 3.41 & 0.76 & 22.80 & 74,187 \\
\hline MB-Ratio & 1.35 & 1.15 & 0.07 & 6.86 & 68,718 \\
\hline NWC/Assets & 0.01 & 0.16 & -0.49 & 0.44 & 71,361 \\
\hline Lt & 23.35 & 17.93 & 0.00 & 79.51 & 74,351 \\
\hline SG & 1.16 & 0.39 & 0.41 & 4.01 & 69,188 \\
\hline R\&D/Sales & 0.02 & 0.04 & 0.00 & 0.21 & 74,022 \\
\hline Capex/Assets & 0.06 & 0.06 & 0.00 & 0.31 & 70,894 \\
\hline Dividend Dummy & 0.53 & 0.50 & 0.00 & 1.00 & 72,983 \\
\hline CF/Assets & 0.10 & 0.08 & -0.15 & 0.35 & 73,431 \\
\hline
\end{tabular}


Table III. Financial constraints and the valuation of cash as a function of ambiguity aversion

This table presents the results of regressions on the excess stock returns distinguishing between two subsamples: the financially constrained and financially unconstrained firms. The main variable of interest is the interaction term, $\Delta \mathrm{Ct} \times$ Ambiguity Aversion. We use dividend payouts to assets, the value of total assets and company age as defining criteria for the level of financial constraints in Columns (1) and (2), (3) and (4) and (5) and (6), respectively. In Columns (1), (3) and (5), we report the results for financially constrained firms and in Columns (2), (4) and (6) for unconstrained firms. Robust standard errors are clustered at the firm level and we use year and industry dummies. All $t$-values are reported under the coefficient estimates. Statistical significance at the $1 \%, 5 \%$ and $10 \%$ level are indicated by $* * *, * *$, and $*$, respectively.

\begin{tabular}{|c|c|c|c|c|c|c|}
\hline & \multicolumn{2}{|c|}{ Dividend Dummy } & \multicolumn{2}{|c|}{ Size Dummy } & \multicolumn{2}{|c|}{ Age Dummy } \\
\hline & Constrained & Unconstrained & Constrained & Unconstrained & Constrained & Unconstrained \\
\hline \multirow{2}{*}{$\Delta C_{t} \times$ Ambiguity Aversion } & $-1.173 * *$ & 0.878 & $-1.560^{* *}$ & 0.306 & $-1.715 * *$ & 0.639 \\
\hline & -2.395 & 1.350 & -2.448 & 0.614 & -2.111 & 1.012 \\
\hline \multirow{2}{*}{$\Delta E_{t}$} & $0.357 * * *$ & $0.350 * * *$ & $0.427 * * *$ & $0.295 * * *$ & $0.385 * * *$ & $0.268 * * *$ \\
\hline & 9.714 & 6.986 & 9.119 & 7.616 & 5.836 & 6.473 \\
\hline \multirow{2}{*}{$\Delta N A_{t}$} & $0.074 * * *$ & $0.098 * * *$ & $0.117 * * *$ & $0.064 * * *$ & $0.099 * * *$ & $0.082 * * *$ \\
\hline & 5.138 & 5.693 & 6.291 & 4.529 & 3.868 & 4.341 \\
\hline \multirow{2}{*}{$\Delta R D_{t}$} & $2.216^{* * *}$ & 1.120 & $4.133^{* * *}$ & -0.369 & $2.329^{* *}$ & -0.509 \\
\hline & 3.288 & 1.603 & 5.390 & -0.646 & 2.013 & -0.926 \\
\hline \multirow{2}{*}{$\Delta I_{t}$} & -0.351 & $-1.194 * * *$ & -0.331 & $-0.962 * *$ & $-1.644 * * *$ & -0.258 \\
\hline & -0.997 & -3.065 & -0.933 & -2.488 & -3.214 & -0.573 \\
\hline \multirow{2}{*}{$\Delta D_{t}$} & $-1.071 * *$ & $1.145^{* * *}$ & $0.907 * * *$ & 0.159 & $1.052 * *$ & 0.109 \\
\hline & -2.050 & 4.978 & 3.281 & 0.485 & 2.551 & 0.284 \\
\hline \multirow{2}{*}{$N F_{t}$} & -0.010 & $-0.078 * *$ & -0.048 & $-0.056^{*}$ & -0.020 & $-0.192 * * *$ \\
\hline & -0.341 & -2.361 & -1.416 & -1.873 & -0.428 & -5.557 \\
\hline \multirow{2}{*}{$\Delta C_{t}$} & $0.696^{* * *}$ & $0.652 * * *$ & $0.768 * * *$ & $0.539 * * *$ & $0.941 * * *$ & $0.454 * * *$ \\
\hline & 12.401 & 11.132 & 12.486 & 9.573 & 10.380 & 7.320 \\
\hline \multirow{2}{*}{$L_{t}$} & $-0.002 * * *$ & $-0.001 * * *$ & $-0.002 * * *$ & $-0.000 *$ & $-0.001 * * *$ & -0.000 \\
\hline & -6.545 & -4.674 & -7.349 & -1.720 & -4.702 & -0.945 \\
\hline \multirow{2}{*}{$C_{t-1}$} & $0.233 * * *$ & $0.182 * * *$ & $0.316^{* * * *}$ & $0.183 * * *$ & $0.286^{* * * *}$ & $0.155^{* * *}$ \\
\hline & 9.751 & 5.422 & 9.480 & 8.358 & 6.739 & 6.480 \\
\hline \multirow{2}{*}{$\Delta C_{t} \times C_{t-1}$} & $-0.176^{* *}$ & $-0.301 * * *$ & $-0.365 * * *$ & -0.082 & -0.076 & $-0.117 *$ \\
\hline & -3.201 & -3.725 & -4.291 & -1.554 & -0.736 & -1.894 \\
\hline \multirow{2}{*}{$\Delta C_{t} \times L_{t}$} & $-0.005 * *$ & -0.004 & $-0.005 * *$ & -0.003 & $-0.009 * *$ & -0.001 \\
\hline & -2.282 & -1.285 & -2.068 & -1.389 & -2.573 & -0.405 \\
\hline \multirow{2}{*}{ Ambiguity Aversion } & $-0.223 * * *$ & -0.059 & $-0.259 * * *$ & $-0.174 * * *$ & $-0.250 * * *$ & $-0.107 *$ \\
\hline & -3.085 & -1.534 & -5.082 & -3.039 & -3.521 & -1.954 \\
\hline \multirow{2}{*}{ Common Law Dummy } & $0.068 * * *$ & $0.015^{*}$ & $0.068 * * *$ & 0.011 & $0.042 * * *$ & 0.004 \\
\hline & 3.900 & 1.688 & 6.086 & 0.874 & 3.002 & 0.307 \\
\hline \multirow{2}{*}{ Inflation } & 0.204 & $1.038 * * *$ & $1.618 * * *$ & $-1.255^{* * *}$ & $0.866^{* *}$ & 0.453 \\
\hline & 0.486 & 3.715 & 4.343 & -2.894 & 2.155 & 1.039 \\
\hline \multirow{2}{*}{ Corruption } & -0.008 & $-0.015 * * *$ & 0.003 & $-0.022 * * *$ & $-0.012 * *$ & $-0.022 * * *$ \\
\hline & -1.298 & -5.108 & 0.570 & -5.306 & -2.164 & -3.356 \\
\hline \multirow{2}{*}{ Total Taxes } & -0.001 & $-0.003 * * *$ & $-0.001 *$ & $-0.006^{* * *}$ & $-0.003 * * *$ & $-0.004 * * *$ \\
\hline & -1.303 & -7.912 & -1.702 & -9.482 & -5.064 & -5.589 \\
\hline \multirow{2}{*}{ Constant } & $0.445^{* *}$ & $1.303 * *$ & 0.351 & $0.887^{* * *}$ & $0.926^{* * *}$ & $0.411^{* *}$ \\
\hline & 2.051 & 2.119 & 1.300 & 6.733 & 3.870 & 2.455 \\
\hline Year Dummies & Yes & Yes & Yes & Yes & Yes & Yes \\
\hline Industry Dummies & Yes & Yes & Yes & Yes & Yes & Yes \\
\hline$R^{2}$ & 0.164 & 0.148 & 0.187 & 0.140 & 0.190 & 0.154 \\
\hline Observations & 13,843 & 17,210 & 14,658 & 16,259 & 7,387 & 11,430 \\
\hline
\end{tabular}


Table IV. Cash holdings and ambiguity aversion

This table presents the results of regressions of cash holdings divided by net assets (Cash/NetAssets) on various firm characteristics. The main variable of interest is our preference parameter, Ambiguity Aversion. We use dividend payouts to assets, the value of total assets and company age as defining criteria for the level of financial constraints in Columns (1) and (2), (3) and (4) and (5) and (6), respectively. In Columns (1), (3) and (5), we report the results for financially constrained firms and in Columns (2), (4) and (6) for unconstrained firms. Robust standard errors are clustered at the firm level and we use year and industry dummies. All $t$-values are reported under the coefficient estimates. Statistical significance at the $1 \%, 5 \%$ and $10 \%$ level are indicated by $* * *, * *$, and $*$, respectively.

\begin{tabular}{|c|c|c|c|c|c|c|}
\hline & \multicolumn{2}{|c|}{ Dividend Dummy } & \multicolumn{2}{|c|}{ Size Dummy } & \multicolumn{2}{|c|}{ Age Dummy } \\
\hline & $\begin{array}{c}\text { Constrai- } \\
\text { ned }\end{array}$ & Unconstrained & Constrained & Unconstrained & Constrained & Unconstrained \\
\hline \multirow{2}{*}{ Ambiguity Aversion } & $-0.309 * * *$ & 0.031 & $-0.500 * * *$ & $0.253 * * *$ & $-0.416^{* * *}$ & 0.081 \\
\hline & -3.902 & 0.640 & -6.790 & 4.703 & -3.592 & 1.587 \\
\hline \multirow{2}{*}{ Real Size } & $-0.003 *$ & 0.001 & $-0.006 * * *$ & $-0.008 * *$ & $0.004 *$ & -0.001 \\
\hline & -1.807 & 0.758 & -2.936 & -2.304 & 1.646 & -0.669 \\
\hline \multirow{2}{*}{ MB-Ratio } & $0.109 * * *$ & $0.068 * * *$ & $0.089 * * *$ & $0.087 * * *$ & $0.102 * * *$ & $0.058 * * *$ \\
\hline & 13.134 & 8.540 & 11.498 & 9.560 & 10.177 & 6.214 \\
\hline \multirow{2}{*}{ NWC/Assets } & $-0.632 * * *$ & $-0.576^{* * *}$ & $-0.647 * * *$ & $-0.526 * * *$ & $-0.844 * * *$ & $-0.377 * * *$ \\
\hline & -14.452 & -14.676 & -15.075 & -12.236 & -13.485 & -8.910 \\
\hline \multirow{2}{*}{$L_{t}$} & $-0.005 * * *$ & $-0.005 * * *$ & $-0.005 * * *$ & $-0.005 * * *$ & $-0.006^{* * *}$ & $-0.004 * * *$ \\
\hline & -15.324 & -17.310 & -14.767 & -14.996 & -14.077 & -12.643 \\
\hline \multirow{2}{*}{$S G$} & $0.054 * * *$ & 0.009 & $0.061 * * *$ & 0.008 & $0.042 * * *$ & $-0.026 * * *$ \\
\hline & 4.810 & 1.034 & 5.401 & 1.067 & 2.832 & -3.234 \\
\hline \multirow{2}{*}{ R\&D/Sales } & $1.903 * * *$ & $1.185 * * *$ & $2.296 * * *$ & $0.910 * * *$ & $1.347 * * *$ & $0.965 * * *$ \\
\hline & 7.890 & 5.770 & 9.400 & 5.325 & 4.468 & 6.706 \\
\hline \multirow{2}{*}{ Dividend Dummy } & . & . & $-0.022 * *$ & $-0.018 * *$ & -0.009 & 0.011 \\
\hline & . & . & -2.469 & -2.419 & -0.663 & -1.545 \\
\hline \multirow{2}{*}{ Capex/Assets } & $-0.757 * * *$ & $-0.931 * * *$ & $-0.702 * * *$ & $-0.974 * * *$ & $-1.113 * * *$ & $-0.751 * * *$ \\
\hline & -10.334 & -11.947 & -9.897 & -11.749 & -9.491 & -7.852 \\
\hline \multirow{2}{*}{ CF/Assets } & $-0.710^{* * *}$ & 0.054 & $-0.612 * * *$ & 0.084 & $-0.358 * *$ & 0.007 \\
\hline & -4.785 & 0.721 & -4.720 & 1.108 & -2.174 & 0.099 \\
\hline \multirow{2}{*}{ Common Law Dummy } & $-0.026^{*}$ & $-0.092 * * *$ & $-0.046 * * *$ & $-0.068 * * *$ & $-0.056^{* *}$ & $-0.088 * * *$ \\
\hline & -1.698 & -10.757 & -3.497 & -6.091 & -2.745 & -8.441 \\
\hline \multirow{2}{*}{ Inflation } & $-0.397 * * *$ & $-0.790 * * *$ & $-0.253 *$ & $-0.515 * * *$ & $-0.722 * * *$ & $-0.383 * * *$ \\
\hline & -3.647 & -6.319 & -1.939 & -4.767 & -4.709 & -4.064 \\
\hline \multirow{2}{*}{ Corruption } & -0.005 & $-0.012 * * *$ & $-0.011 * * *$ & -0.003 & $-0.017 * * *$ & -0.005 \\
\hline & -1.153 & -4.053 & -2.596 & -1.142 & -3.124 & -1.522 \\
\hline \multirow{2}{*}{ Total Taxes } & $-0.001 * *$ & $-0.002 * * *$ & $-0.002 * * *$ & -0.001 & 0.000 & $-0.001 *$ \\
\hline & -2.162 & -3.988 & -4.643 & -1.147 & -0.652 & -1.814 \\
\hline \multirow{2}{*}{ Constant } & $0.371^{* * *}$ & $0.483 * * *$ & $0.514^{* * *}$ & $0.447^{* * *}$ & $0.230 * * *$ & $0.387 * * *$ \\
\hline & 5.673 & 6.919 & 7.985 & 4.992 & 2.454 & 5.746 \\
\hline Year Dummies & Yes & Yes & Yes & Yes & Yes & Yes \\
\hline Industry Dummies & Yes & Yes & Yes & Yes & Yes & Yes \\
\hline Observations & 21,145 & 24,330 & 22,850 & 22,625 & 11,931 & 17,008 \\
\hline
\end{tabular}


Table $V$. Foreign ownership and the valuation of cash as a function of ambiguity aversion

This table presents the results of the same regression model as in Table III only for companies with Foreign Ownership $>30 \%$. We again contrast the financially constrained and unconstrained firms using dummies based on dividend payouts, the value of total assets and company age as defining criteria for the level of financial constraints in Columns (1) and (2), (3) and (4) and (5) and (6), respectively. In Columns (1), (3) and (5), we report the results for financially constrained firms and in Columns (2), (4) and (6) for unconstrained firms. Robust standard errors are clustered at the firm level and we use year and industry dummies. All $t$-values are reported under the coefficient estimates. Statistical significance at the $1 \%, 5 \%$ and $10 \%$ level are indicated by $* * *, * *$, and $*$, respectively.

\begin{tabular}{|c|c|c|c|c|c|c|}
\hline & \multicolumn{2}{|c|}{ Dividend Dummy } & \multicolumn{2}{|c|}{ Size Dummy } & \multicolumn{2}{|c|}{ Age Dummy } \\
\hline & Constrained & Unconstrained & Constrained & Unconstrained & Constrained & Unconstrained \\
\hline \multirow{2}{*}{$\Delta C_{t} \times$ Ambiguity Aversion } & 2.652 & 2.633 & -0.833 & 3.065 & 4.045 & 4.522 \\
\hline & 1.200 & 1.105 & -0.401 & 1.035 & 1.265 & 0.991 \\
\hline \multirow{2}{*}{$\Delta E_{t}$} & $0.462 * * *$ & 0.013 & $0.408 * * *$ & $0.393 *$ & 0.466 & $0.430 * *$ \\
\hline & 2.851 & 0.057 & 2.602 & 1.737 & 1.464 & 2.387 \\
\hline \multirow{2}{*}{$\triangle N A_{t}$} & 0.075 & $0.144^{*}$ & 0.068 & 0.041 & 0.008 & 0.100 \\
\hline & 1.457 & 1.710 & 0.977 & 0.647 & 0.121 & 1.299 \\
\hline \multirow{2}{*}{$\Delta R D_{t}$} & -0.672 & -0.094 & -2.049 & 4.422 & -3.404 & -4.609 \\
\hline & -0.169 & -0.026 & -0.403 & 1.352 & -0.396 & -1.235 \\
\hline \multirow{2}{*}{$\Delta I_{t}$} & -0.793 & -3.199 & $-2.948 *$ & 0.584 & -2.362 & -2.09 \\
\hline & -0.469 & -1.280 & -1.735 & 0.320 & -1.320 & -1.332 \\
\hline \multirow{2}{*}{$\Delta D_{t}$} & -1.923 & $1.538 * *$ & $1.363^{*}$ & 0.712 & $2.499 * *$ & $2.625^{*}$ \\
\hline & -1.241 & 2.147 & 1.914 & 0.607 & 2.104 & 1.844 \\
\hline \multirow{2}{*}{$N F_{t}$} & 0.128 & 0.171 & -0.079 & 0.111 & 0.271 & -0.117 \\
\hline & 1.216 & 1.319 & -0.615 & 0.926 & 1.642 & -0.508 \\
\hline \multirow{2}{*}{$\Delta C_{t}$} & 0.285 & 0.303 & $0.410^{* *}$ & 0.258 & $0.975 * * *$ & 0.625 \\
\hline & 1.217 & 1.311 & 1.994 & 0.824 & 2.736 & 1.659 \\
\hline \multirow{2}{*}{$L_{t}$} & $-0.004 * *$ & -0.002 & $-0.003 * *$ & $-0.004^{* *}$ & $-0.004^{* *}$ & $-0.003 *$ \\
\hline & -2.394 & -1.377 & -2.408 & -2.473 & -2.402 & -1.682 \\
\hline \multirow{2}{*}{$C_{t}$} & $0.379 * * *$ & $0.349 * *$ & $0.396^{* * *}$ & $0.344 * * *$ & $0.843 * * *$ & 0.052 \\
\hline & 4.144 & 2.474 & 3.697 & 3.517 & 4.498 & 0.448 \\
\hline \multirow{2}{*}{$\Delta C_{t} \times C_{t}$} & -0.291 & 0.142 & $-0.738 * * *$ & -0.041 & -0.626 & $-0.683^{* * *}$ \\
\hline & -1.336 & 0.699 & -3.606 & -0.21 & -1.018 & -2.777 \\
\hline \multirow{2}{*}{$\Delta C_{t} \times L_{t}$} & -0.005 & -0.007 & -0.009 & -0.01 & -0.015 & $0.053 * * *$ \\
\hline & -0.383 & -0.405 & -0.847 & -0.792 & -0.885 & 2.656 \\
\hline \multirow{2}{*}{ Ambiguity Aversion } & -0.284 & $0.516^{* *}$ & -0.084 & -0.044 & 0.196 & 0.307 \\
\hline & -0.871 & 2.182 & -0.352 & -0.127 & 0.349 & 0.677 \\
\hline \multirow{2}{*}{ Common Law Dummy } & -0.010 & 0.075 & $0.090^{* *}$ & -0.025 & -0.018 & -0.014 \\
\hline & -0.146 & 1.538 & 2.151 & -0.351 & -0.284 & -0.161 \\
\hline \multirow{2}{*}{ Inflation } & 3.002 & -0.251 & 0.603 & 0.509 & 1.78 & 2.486 \\
\hline & 1.559 & -0.299 & 0.498 & 0.383 & 1.189 & 1.188 \\
\hline \multirow{2}{*}{ Corruption } & -0.002 & -0.011 & -0.006 & -0.026 & -0.017 & -0.006 \\
\hline & -0.067 & -0.949 & -0.367 & -1.305 & -0.712 & -0.196 \\
\hline \multirow{2}{*}{ Total Taxes } & $-0.005 *$ & -0.002 & 0.000 & $-0.006^{* *}$ & -0.001 & -0.002 \\
\hline & -1.697 & -1.110 & 0.166 & -2.424 & -0.23 & -0.915 \\
\hline \multirow{2}{*}{ Constant } & -0.272 & 0.261 & -0.28 & $0.556^{* *}$ & 0.309 & 0.207 \\
\hline & -0.777 & 1.482 & -1.222 & 2.11 & 0.809 & 0.495 \\
\hline Year Dummies & Yes & Yes & Yes & Yes & Yes & Yes \\
\hline Industry Dummies & Yes & Yes & Yes & Yes & Yes & Yes \\
\hline$R^{2}$ & 0.354 & 0.262 & 0.28 & 0.342 & 0.506 & 0.363 \\
\hline Observations & 530 & 864 & 703 & 661 & 302 & 283 \\
\hline
\end{tabular}


Table VI. Foreign ownership and the relationship between cash holdings and ambiguity aversion

This table presents the results of the same regression model as in Table IV only for companies with Foreign Ownership $>30 \%$. We use dividend payouts to assets, the value of total assets and company age as defining criteria for the level of financial constraints in Columns (1) and (2), (3) and (4) and (5) and (6), respectively. In Columns (1), (3) and (5), we report the results for financially constrained firms and in Columns (2), (4) and (6) for unconstrained firms. Robust standard errors are clustered at the firm level and we use year and industry dummies. All $t$-values are reported under the coefficient estimates. Statistical significance at the $1 \%, 5 \%$ and $10 \%$ level are indicated by ***, **, and $*$, respectively.

\begin{tabular}{|c|c|c|c|c|c|c|}
\hline & \multicolumn{2}{|c|}{ Dividend Dummy } & \multicolumn{2}{|c|}{ Size Dummy } & \multicolumn{2}{|c|}{ Age Dummy } \\
\hline & Constrained & Unconstrained & Constrained & Unconstrained & Constrained & Unconstrained \\
\hline \multirow{2}{*}{ Ambiguity Aversion } & -0.562 & 0.125 & -0.324 & -0.125 & $-1.078 * *$ & -0.189 \\
\hline & -1.497 & 0.554 & -0.902 & -0.484 & -2.26 & -0.873 \\
\hline \multirow{2}{*}{ Real Size } & -0.003 & 0.001 & -0.001 & $-0.018^{*}$ & -0.006 & 0.003 \\
\hline & -0.592 & 0.203 & -0.190 & -1.811 & -0.917 & 0.797 \\
\hline \multirow{2}{*}{ MB-Ratio } & $0.067 * * *$ & $0.065 * * *$ & $0.065 * * *$ & $0.047 * * *$ & $0.093 * * *$ & 0.014 \\
\hline & 2.736 & 3.331 & 2.969 & 2.659 & 3.487 & 0.739 \\
\hline \multirow{2}{*}{ NWC/Assets } & $-0.463 * * *$ & $-0.564 * * *$ & $-0.542 * * *$ & $-0.383 * * *$ & $-0.768 * * *$ & $-0.475 * * *$ \\
\hline & -3.494 & -4.534 & -4.271 & -3.872 & -3.883 & -3.045 \\
\hline \multirow{2}{*}{$L_{t}$} & $-0.006 * * *$ & $-0.006^{* * *}$ & $-0.006^{* * *}$ & $-0.004 * * *$ & $-0.008 * * *$ & $-0.002 * * *$ \\
\hline & -5.505 & -5.347 & -5.076 & -4.071 & -5.064 & -2.946 \\
\hline \multirow{2}{*}{$S G$} & 0.033 & 0.086 & 0.086 & -0.027 & 0.087 & $-0.039 *$ \\
\hline & 0.934 & 1.062 & 1.390 & -1.088 & 0.720 & -1.992 \\
\hline \multirow{2}{*}{$R \& D /$ Sales } & 1.000 & $1.774 * *$ & $1.889^{* *}$ & 1.129 & 1.282 & $2.090 * * *$ \\
\hline & 1.090 & 2.041 & 2.037 & 1.215 & 1.161 & 3.296 \\
\hline \multirow{2}{*}{ Dividend Dummy } & . & . & -0.006 & -0.035 & -0.015 & 0.002 \\
\hline & . & . & -0.213 & -1.440 & -0.385 & 0.122 \\
\hline \multirow{2}{*}{ Capex/Assets } & $-0.623 * *$ & $-0.663 * * *$ & $-0.464 *$ & $-0.595 * * *$ & $-1.305 * * *$ & -0.116 \\
\hline & -2.448 & -2.809 & -1.867 & -3.146 & -2.876 & -0.388 \\
\hline \multirow{2}{*}{ CF/Assets } & -0.374 & -0.168 & -0.436 & $0.713 * * *$ & -0.569 & $0.280 * *$ \\
\hline & -1.002 & -0.567 & -1.357 & 3.66 & -1.228 & 2.013 \\
\hline \multirow{2}{*}{ Common Law Dummy } & 0.008 & -0.004 & -0.013 & -0.055 & -0.081 & -0.001 \\
\hline & 0.163 & -0.113 & -0.248 & -1.525 & -1.155 & -0.030 \\
\hline \multirow{2}{*}{ Inflation } & 0.461 & 0.012 & -0.579 & 0.314 & -2.067 & -0.804 \\
\hline & 0.543 & 0.020 & -0.836 & 0.508 & -1.571 & -1.564 \\
\hline \multirow{2}{*}{ Corruption } & -0.006 & -0.003 & -0.015 & -0.005 & -0.028 & $-0.032 * *$ \\
\hline & -0.381 & -0.285 & -1.227 & -0.402 & -1.446 & -2.284 \\
\hline \multirow{2}{*}{ Total Taxes } & $-0.003 * *$ & $-0.002 * *$ & -0.002 & $-0.004 * * *$ & -0.005 & -0.000 \\
\hline & -2.037 & -2.185 & -1.436 & -3.227 & -1.595 & -0.426 \\
\hline \multirow{2}{*}{ Constant } & $0.693 * * *$ & 0.254 & $0.471^{* *}$ & $0.875 * * *$ & $1.320 * * *$ & $0.381 * *$ \\
\hline & 3.048 & 1.882 & 2.515 & 3.483 & 2.619 & 2.422 \\
\hline Year Dummies & Yes & Yes & Yes & Yes & Yes & Yes \\
\hline Industry Dummies & Yes & Yes & Yes & Yes & Yes & Yes \\
\hline Observations & 21,145 & 24,330 & 22,850 & 22,625 & 11,931 & 17,008 \\
\hline
\end{tabular}


Table VII. Valuation of cash holdings depending on ambiguity aversion and risk aversion

This table presents the results of regressions of the excess stock returns on changes in firm characteristics over the fiscal year. Our main variables of interest are $\Delta C_{\mathrm{t}} \times$ Ambiguity Aversion and $\Delta C_{t} \times$ Risk Aversion. Robust standard errors are clustered at the firm level and we use year and industry dummies. All $t$ values are reported under the coefficient estimates. Statistical significance at the $1 \%, 5 \%$ and $10 \%$ level are indicated by $* * *, * *$, and $*$, respectively.

\begin{tabular}{|c|c|c|c|c|c|c|}
\hline & \multicolumn{2}{|c|}{ Dividend Dummy } & \multicolumn{2}{|c|}{ Size Dummy } & \multicolumn{2}{|c|}{ Age Dummy } \\
\hline & Constrained & Unconstrained & Constrained & Unconstrained & Constrained & Unconstrained \\
\hline \multirow{2}{*}{$\Delta C_{t} \times$ Ambiguity Aversion } & $-1.109 *$ & 1.030 & $-1.691 * *$ & 0.775 & $-1.998 * *$ & 1.088 \\
\hline & -1.889 & 1.512 & -2.312 & 1.398 & -2.258 & 1.006 \\
\hline \multirow{2}{*}{$\Delta C_{t} \times$ Risk Aversion } & 0.269 & 1.01 & -0.528 & $2.173 * *$ & -1.091 & 1.241 \\
\hline & 0.234 & 0.884 & -0.418 & 2.053 & -0.765 & 0.550 \\
\hline Other Controls & Yes & Yes & Yes & Yes & Yes & Yes \\
\hline Year Dummies & Yes & Yes & Yes & Yes & Yes & Yes \\
\hline Industry Dummies & Yes & Yes & Yes & Yes & Yes & Yes \\
\hline$R^{2}$ & 0.164 & 0.148 & 0.187 & 0.141 & 0.190 & 0.155 \\
\hline Observations & 13,843 & 17,210 & 14,658 & 16,259 & 7,387 & 11,430 \\
\hline
\end{tabular}

Table VIII. Amount of cash holdings depending on ambiguity aversion and risk aversion

This table presents the results of regressions of cash holdings divided by net assets (Cash/Net Assets) on various firm characteristics. Our main variables of interest are Ambiguity Aversion and Risk Aversion. Robust standard errors are clustered at the firm level and we use year and industry dummies. All $t$ values are reported under the coefficient estimates. Statistical significance at the $1 \%, 5 \%$ and $10 \%$ level are indicated by $* * *, * *$, and $*$, respectively.

\begin{tabular}{|c|c|c|c|c|c|c|}
\hline & \multicolumn{2}{|c|}{ Dividend Dummy } & \multicolumn{2}{|c|}{ Size Dummy } & \multicolumn{2}{|c|}{ Age Dummy } \\
\hline & Constrained & Unconstrained & Constrained & Unconstrained & Constrained & Unconstrained \\
\hline \multirow{2}{*}{ Ambiguity Aversion } & $-0.313 * * *$ & 0.068 & $-0.435 * * *$ & $0.317 * * *$ & $-0.540 * * *$ & $0.170 * *$ \\
\hline & -3.423 & 1.149 & -5.252 & 4.875 & -4.176 & 2.477 \\
\hline \multirow{2}{*}{ Risk Aversion } & -0.015 & 0.110 & $0.245^{*}$ & $0.187 *$ & $-0.349 * *$ & $0.248 * *$ \\
\hline & -0.112 & 1.127 & 1.815 & 1.798 & -2.282 & 2.003 \\
\hline Other Controls & Yes & Yes & Yes & Yes & Yes & Yes \\
\hline Year Dummies & Yes & Yes & Yes & Yes & Yes & Yes \\
\hline Industry Dummies & Yes & Yes & Yes & Yes & Yes & Yes \\
\hline Observations & 21,145 & 24,330 & 22,850 & 22,625 & 11,931 & 17,008 \\
\hline
\end{tabular}


Table IX. Amount of cash holdings depending on ambiguity aversion and culture

This table presents the results of regressions of cash holdings divided by net assets (Cash/Net Assets) on various firm characteristics. Our main variables of interest are Ambiguity Aversion, Uncertainty Avoidance and Individualism. Robust standard errors are clustered at the firm level and we use year and industry dummies. All $t$-values are reported under the coefficient estimates. Statistical significance at the $1 \%, 5 \%$ and $10 \%$ level are indicated by $* * *, * *$, and $*$, respectively.

\begin{tabular}{|c|c|}
\hline \multirow{2}{*}{ Ambiguity Aversion } & \\
\cline { 2 - 2 } & $-0.346^{* * *}$ \\
\hline \multirow{2}{*}{ Uncertainty Avoidance } & -6.29 \\
\cline { 2 - 2 } & $-0.002^{* * *}$ \\
\hline \multirow{2}{*}{ Individualism } & -5.60 \\
\cline { 2 - 2 } & 0.001 \\
\hline Other Controls & $2.17^{* *}$ \\
\hline Year Dummies & Yes \\
\hline Industry Dummies & Yes \\
\hline Observations & Yes \\
\hline
\end{tabular}




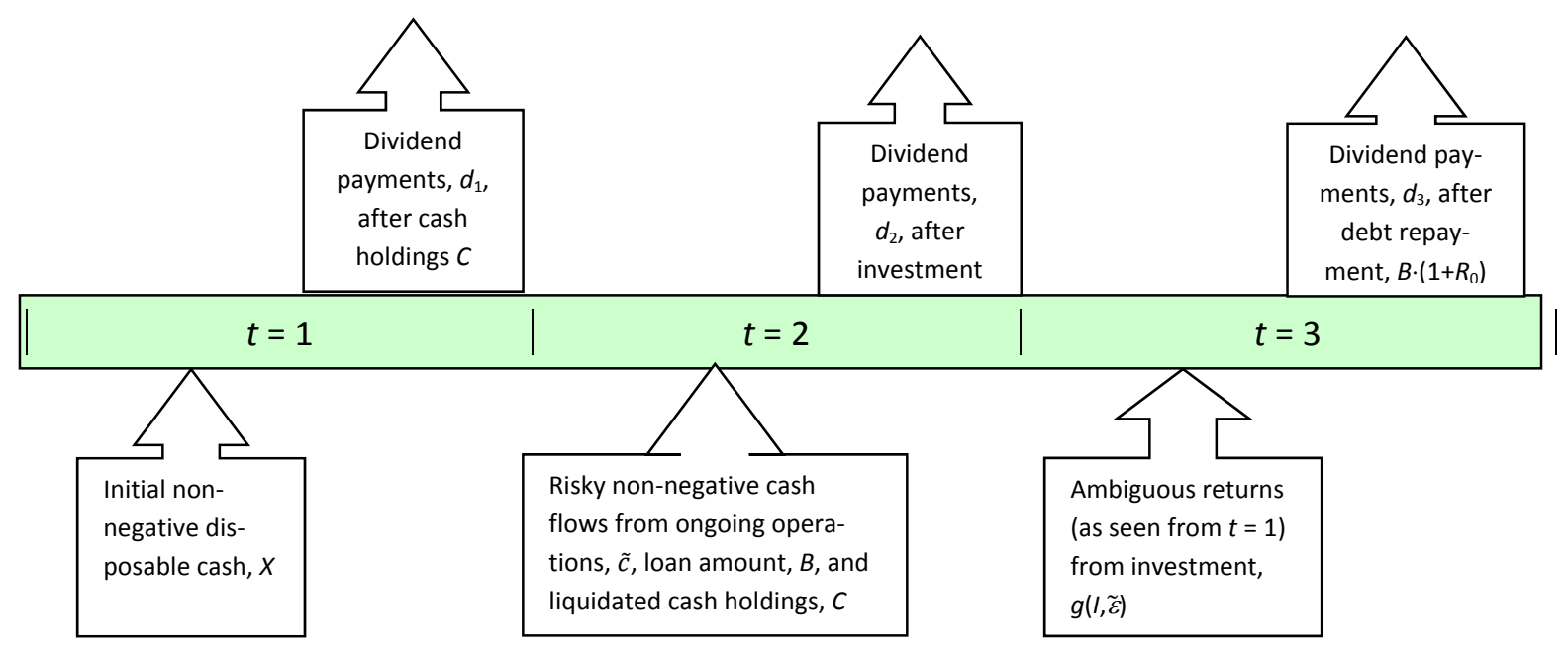

Figure I. Illustration of our three-period model. 